\title{
Precipitates of Cubic Structure Detected \\ in Low-Carbon Aluminum-Killed Steels*
}

By Satoshi HANAI, ${ }^{* *}$ Nagayasu TAKEMOTO, ${ }^{* *}$ and Yaichiro MIZUYAMA**

\section{Synopsis}

The precifitation and recrystallization behaviors of two aluminum-killed steels were investigated in isothermal annealing and in continuous heating, starting with either as hot-rolled (as taken from productional hot coils) or as cold-rolled ( $\mathrm{ca} .70 \%)$.

Careful electron microscopy (carbon extraction replica), nun along with the measurement of solute nitrogen by internal friction, revealed that, even when no evidence of ordinary AIN precipitation is apparent, there is definitely some precipitation of $\mathrm{AIN}$ of almost sub-electron microscopic sizes. The electron diffraction pattern of those minute $\mathrm{AIN}$ precipitates did not conform to that of hexagonal $\mathrm{AlN}$, but fit very well with that of a hypothetical cubic AlN of $\mathrm{NaCl}$ type structure with $a=4.047 \AA$.

\section{Introduction}

Since R. S. Burns and A. S. McCabe ${ }^{1)}$ showed that aluminum-killed steel sheets had excellent deep drawing qualities, many studies of the recrystallization behavior have been done, and it has been pointed out that the recrystallization behavior of cold-worked aluminum-killed steels is profoundly associated with the precipitation of aluminum nitride (AIN) during recrystallization annealing. ${ }^{2)-19)}$ However, it was often that AIN particles were not detected by chemical analysis due to Beeghly ${ }^{20)}$ or by extraction replica technique and the direct observation of thin foils before or during recrystallization, ${ }^{12), 13), 15), 18)}$ even though the solute nitrogen measured by internal friction technique had already been decreased.5),6),18) From experimental results as mentioned above, it has come to be presumed that the effective precipitates were in the state of pre-precipitation clusters of $\mathrm{AIN},{ }^{5), 6), 12), 13), 15), 18)}$ but such clusters have never been experimentally recognized.

By extraction replica method, the authors have been able to show that particles of cubic lattice structure precipitate while the ordinary AIN precipitates of hexagonal lattice structure have not, as yet, make their appearances, and have recognized that cubic lattice precipitates are closely related to the recrystallization behavior. This is a report centering around the precipitation behavior and structure of cubic precipitates in low-carbon aluminum-killed steels.

\section{Material and Procedure}

The materials used in this study were two com- mercial low-carbon aluminum-killed steels that were hot-rolled with a finishing temperature of about $860^{\circ} \mathrm{C}$ and then coiled at about $500^{\circ} \mathrm{C}$. Their chemical compositions are shown in Table 1 .

Heat treatments were carried out in two ways. In one case hot-rolled strips and cold-rolled strips (70\% reduction in an experimental cold-rolling mill) were isothermally annealed in an argon atmosphere and then water-quenched. In the other case coldrolled specimens that were given one of three different

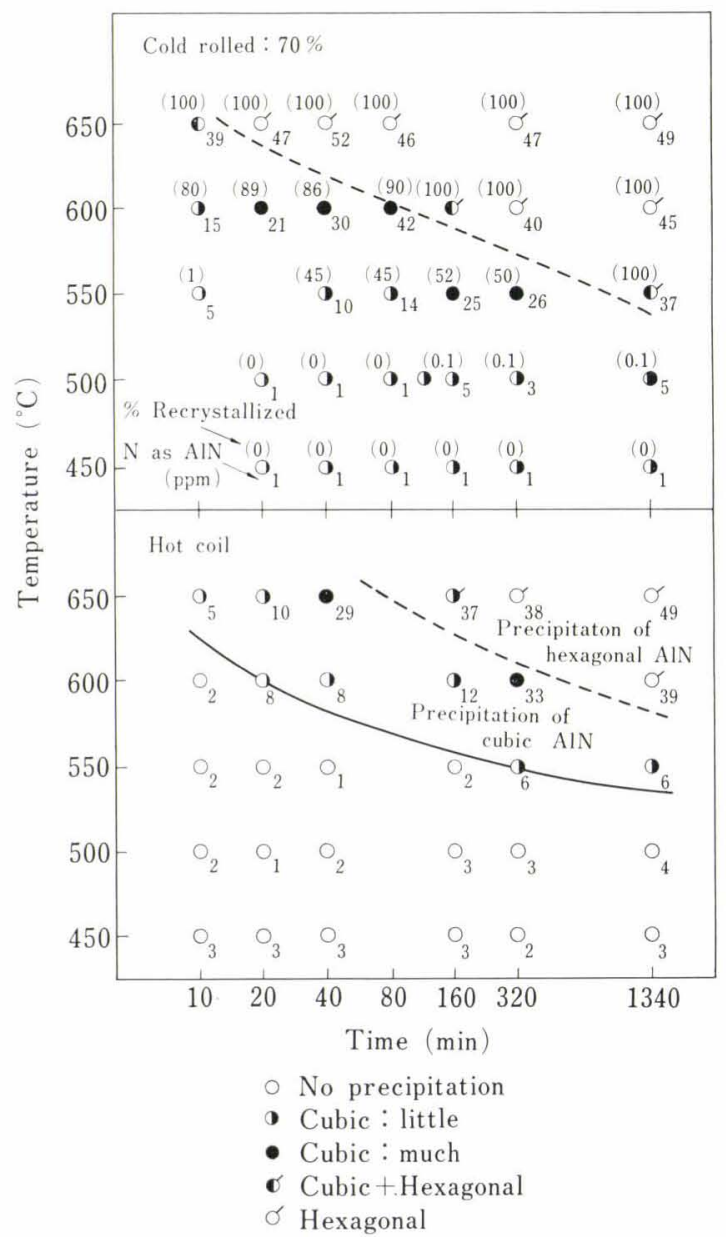

Fig. 1. Change in precipitation in hot-rolled or cold-rolled strips as annealed isothermally, steel HA

Table 1. Chemical compositions of samples (wt \%)

\begin{tabular}{c|c|c|c|c|c|c|c|c|c|c|c|c|c|c|}
\hline Steel & $\mathrm{C}$ & $\mathrm{Si}$ & $\mathrm{Mn}$ & $\mathrm{P}$ & $\mathrm{S}$ & $\mathrm{Sol}$ Al & Sol. N & $\mathrm{N}$ as AlN & 0.0003 \\
\hline LA & 0.045 & 0.019 & 0.32 & 0.004 & 0.017 & 0.038 & 0.0048 \\
\hline HA & 0.058 & 0.018 & 0.35 & 0.008 & 0.018 & 0.060 & 0.0054 & 0.0002 \\
\hline
\end{tabular}

* Presented at the 79th ISIJ Meeting, April, 1970, in Tokyo. Manuscript received August $25,1970$.

** Nagoya Iron Works, Nippon Steel Corp., Tokai-cho, Tokai 476. 
pretreatments were quenched in silicon oil from predetermined temperatures in the course of continuous heating in vacuum. The three different conditions were as follows: no pretreatment; isothermal precipitation annealing in an argon atmosphere for two hours at $600^{\circ} \mathrm{C}$ for hot-rolled strips ; and the same except at $500^{\circ} \mathrm{C}$ for cold-rolled strips. Three different rates were employed for the continuous heating: $30^{\circ} \mathrm{C} / \mathrm{hr} ; 720^{\circ} \mathrm{C} / \mathrm{hr}$; and $720^{\circ} \mathrm{C} / \mathrm{hr}$ up to $560^{\circ} \mathrm{C}$ and $30^{\circ} \mathrm{C} / \mathrm{hr}$ thereafter.

For each test piece thus prepared, examination was made by means of Rockwell hardness, percentage recrystallized, grain size and its elongation ratio after complete recrystallization, behavior of precipitates by extraction replica method, identification of precipitates by selected area diffraction method, direct observation of thin foils, and X-ray intensities of diffraction peaks.

Specimens for extraction replica method were prepared as follows : the longitudinal section was ground with emery paper (to \#1000), etched in an aqueous solution of oxalic acid $(100 \mathrm{~g} / l)$ and hydrogen peroxide at a volume fraction of $7: 1: 20$ (water), deposited with carbon, and the carbon replica was rapidly stripped by electrolysis.

The solute nitrogen of hot-rolled strips, as isothermally annealed in salt bath, was determined by internal friction on 30 logarithmic decrement values measured between $-40^{\circ}$ and $130^{\circ} \mathrm{C}$ at $1.5 \mathrm{~Hz}$.

\section{Results}

Precipitation behavior of particles in hot-rolled and cold-rolled strips as annealed isothermally in an argon atmosphere, as determined by extraction replica technique and chemical analysis, is shown in Fig. 1. Precipitates observed in hot-rolled strips by extraction replica method are shown in Photo. 1, and those in cold-rolled strips in Photo. 2. The analysis of electron diffraction pattern of particles in hot-rolled strips is shown in Table 2, and that in cold-rolled strips in Table 3. From Tables 2 and 3, it is seen that there are precipitates that can be explained by assuming that the particles have cubic structure (called thereafter the cubic precipitates (or particles) for short), besides the hexagonal ones, which have long been recognized. The cubic precipitates will be discussed in $I V-1$.

The electron diffraction pattern and microphoto-
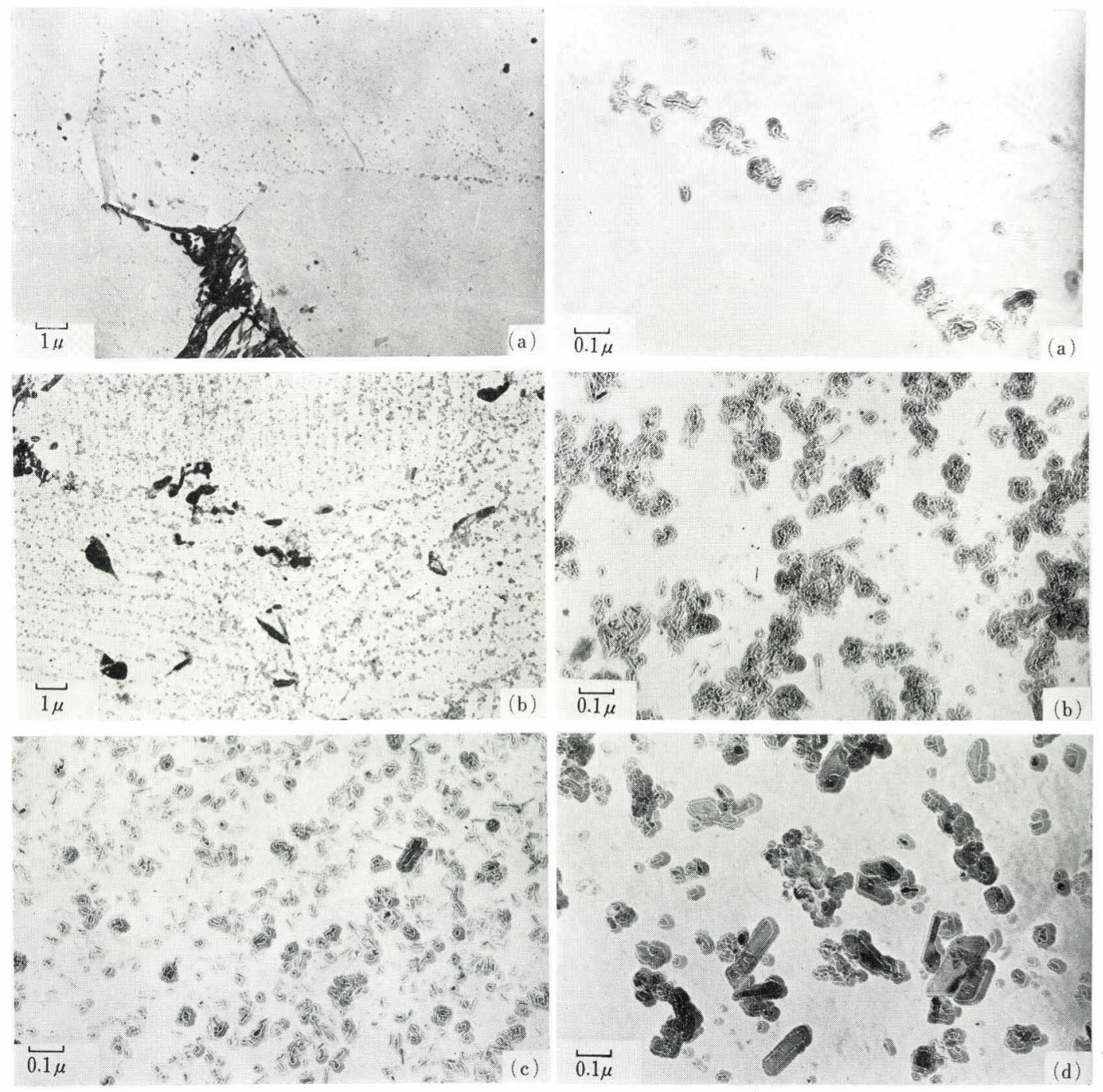

Photo. 1. Change in precipitates as seen by extraction replica method in hot-rolled strips during isothermal annealing, steel HA
(a) Cubic precipitates at grain boundaries
(c) Fine hexagonal precipitates
(b) Cubic precipitates in grains
(d) Coarse hexagonal precipitates 

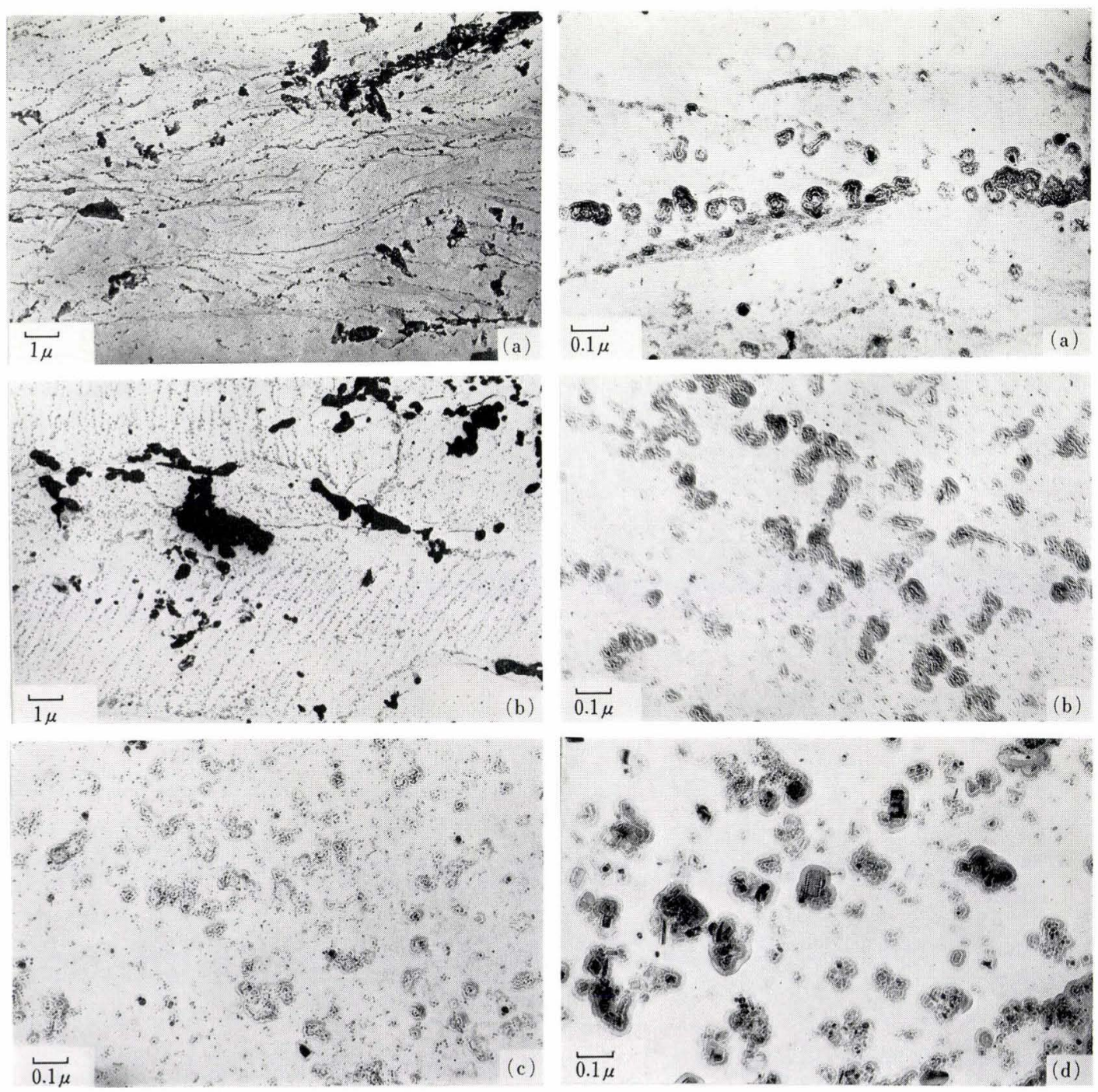

Photo. 2. Change in precipitates as seen by extraction replica method in cold-rolled strips during isothermal annealing, steel HA
(a) Cubic precipitates at deformed grain boundaries or deformation bands
(c) Fine hexagonal precipitates
(b) Cubic precipitates in recrystallized grains
(d) Coarse hexagonal precipitates

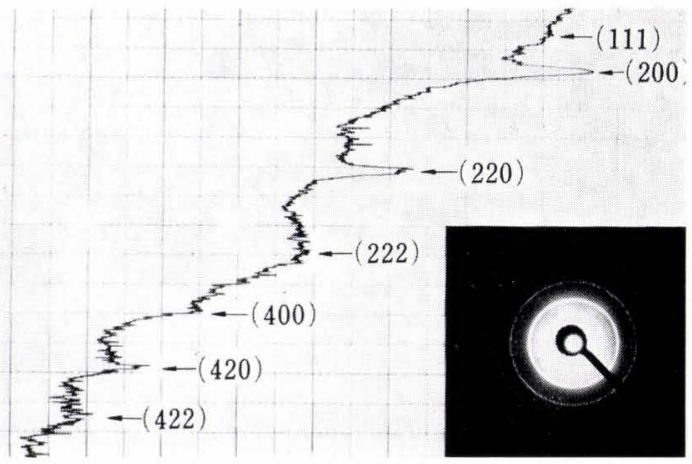

Fig. 2. Electron diffraction pattern and its microphotometer curve of the cubic precipitates in a hot-rolled strip, steel HA

meter curve of cubic precipitates are shown in Fig. 2, while Fig. 3 shows the solute nitrogen, $\mathrm{N}$ as AlN, by chemical analysis and the precipitation of particles as observed by extraction replica method in a function of the time of isothermal annealing conducted in a salt bath for hot-rolled strips.

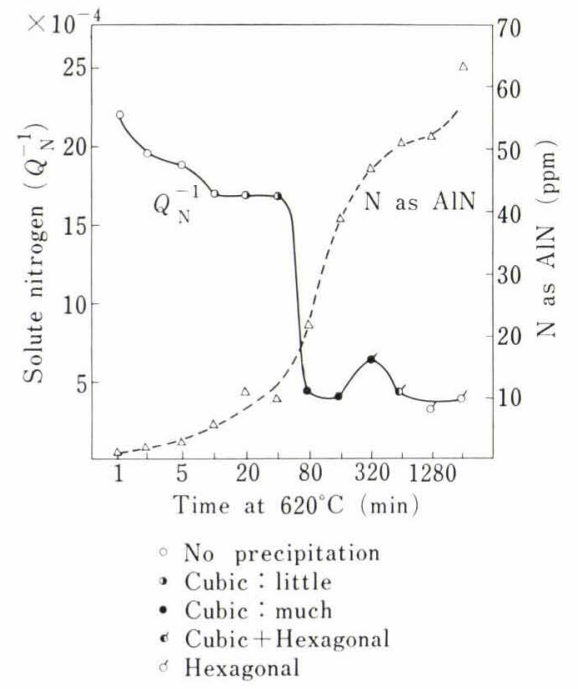

Fig. 3. Change in solute nitrogen by internal friction measurements, $\mathrm{N}$ as $\mathrm{AlN}$ by chemical analysis, and nature of precipitates as seen by extraction replica method in hot-rolled strips during isothermal annealing, steel LA 
Table 2. Analysis of electron diffraction pattern of precipitates in hot strips (steel HA), as annealed isothermally

\begin{tabular}{|c|c|c|c|c|c|c|c|c|c|c|c|c|c|c|c|c|c|c|c|c|c|}
\hline \multirow{2}{*}{\multicolumn{3}{|c|}{$\begin{array}{c}\text { AlN } \\
\text { (ASTM8-262) } \\
a_{0}=3.114 \\
c_{0}=4.986\end{array}$}} & \multirow{2}{*}{\multicolumn{3}{|c|}{$\begin{array}{c}\text { Cubic AlN } \\
\text { (assumed) } \\
a_{0}=4.047 \\
\lambda=0.037\end{array}$}} & \multirow{2}{*}{\multicolumn{2}{|c|}{$\frac{550^{\circ} \mathrm{C}}{1340 \mathrm{~min}}$}} & \multicolumn{6}{|c|}{$600^{\circ} \mathrm{C}$} & \multicolumn{8}{|c|}{$650^{\circ} \mathrm{C}$} \\
\hline & & & & & & & & \multicolumn{2}{|c|}{$20 \mathrm{~min}$} & \multicolumn{2}{|c|}{$320 \mathrm{~min}$} & \multicolumn{2}{|c|}{$1340 \mathrm{~min}$} & \multicolumn{2}{|c|}{$10 \mathrm{~min}$} & \multicolumn{2}{|c|}{$40 \mathrm{~min}$} & \multicolumn{2}{|c|}{$160 \mathrm{~min}$} & \multicolumn{2}{|c|}{$320 \mathrm{~min}$} \\
\hline$d \AA$ & $I / I_{1}$ & hkl & $d \AA$ & $I / I_{1}$ & hkl & $d \AA$ & $I / I_{1}$ & $d \AA$ & $I / I_{1}$ & $d \AA$ & $I / I_{1}$ & $d \AA$ & $I / I_{1}$ & $d \AA$ & $I / I_{1}$ & $d \AA$ & $I / I_{1}$ & $d \AA$ & $I / I_{1}$ & $d \AA$ & $I / I_{1}$ \\
\hline 2.70 & 100 & 100 & & & & & & & & & & 2.715 & $\mathrm{~S}$ & & & 2.693 & Spot & 2.704 & Spot & 2.706 & M \\
\hline 2.49 & 60 & 002 & & & & & & & & & & 2.506 & W & & & 2.506 & Spot & 2.499 & Spot & 2.497 & W \\
\hline 2.372 & 70 & 101 & & & & & & & & & & 2.378 & W & & & 2.361 & Spot & 2.373 & Spot & 2.370 & W \\
\hline & & & 2.336 & 14 & 111 & & & & & 2.340 & W & 2.327 & W & & & 2.327 & W & 2.323 & W & & \\
\hline & & & 2.023 & 100 & 200 & 2.029 & VW & 2.024 & VW & 2.024 & $\mathrm{~S}$ & 2.011 & W & 2.004 & VW & 2.011 & $\mathrm{~S}$ & 2.024 & $\mathrm{~S}$ & & \\
\hline 1.829 & 21 & 102 & & & & & & & & & & 1.820 & VW & & & & & & & 1.824 & VW \\
\hline 1.557 & 30 & 110 & & & & & & & & & & 1.552 & $\mathrm{M}$ & & & 1.552 & Spot & 1.556 & W & 1.546 & $\mathrm{~S}$ \\
\hline & & & 1.431 & 42 & 220 & 1.430 & VW & 1.435 & VW & 1.428 & $\mathrm{M}$ & & & 1.437 & VW & 1.423 & M & 1.434 & M & & \\
\hline 1.414 & 21 & 103 & & & & & & & & & & 1.417 & VW & & & & & & & 1.412 & W \\
\hline 1.348 & 5 & 200 & & & & & & & & & & & & & & & & & & 1.342 & VW \\
\hline 1.320 & 17 & 112 & & & & & & & & & & 1.335 & VW & & & & & 1.336 & VW & 1.320 & W \\
\hline 1.301 & 7 & 201 & & & & & & & & & & 1.309 & VW & & & & & & & & \\
\hline & & & 1.220 & 1 & 311 & & & & & & & & & & & & & & & & \\
\hline 1.186 & 4 & 202 & 1.168 & 11 & 222 & & & & & 1.178 & W & & & & & 1.168 & Spot & 1.178 & W & 1.194 & VW \\
\hline 1.047 & 6 & 203 & & & & & & & & & & & & & & & & & & 1.041 & VW \\
\hline 1.019 & 3 & 210 & 1.012 & 4 & 400 & & & & & 1.012 & W & & & & & 1.006 & VW & 1.012 & VW & & \\
\hline 0.9984 & 5 & 211 & & & & & & & & & & & & & & & & & & 0.984 & VW \\
\hline 0.9345 & 5 & 105 & 0.928 & 0.4 & 331 & & & & & & & & & & & & & & & & \\
\hline & & & 0.905 & 10 & 420 & & & & & 0.909 & $\mathrm{M}$ & & & & & 0.903 & W & 0.904 & M & & \\
\hline 0.8684 & 6 & 213 & 0.826 & 6 & 422 & & & & & 0.829 & W & & & & & 0.825 & VW & 0.827 & W & & \\
\hline
\end{tabular}

Table 3. Analysis of electron diffraction pattern of precipitates in cold-rolled strips (steel HA), as annealed isothermally

\begin{tabular}{|c|c|c|c|c|c|c|c|c|c|c|c|c|c|c|c|c|c|c|c|c|c|}
\hline \multirow{2}{*}{\multicolumn{3}{|c|}{$\begin{array}{c}\text { AIN } \\
\text { (ASTM8-262) } \\
a_{0}=3.114 \\
c_{0}=4.986\end{array}$}} & \multirow{2}{*}{\multicolumn{3}{|c|}{$\begin{array}{c}\text { Cubic AlN } \\
\text { (assumed) } \\
a_{0}=4.047 \\
\lambda=0.037\end{array}$}} & \multirow{2}{*}{\multicolumn{2}{|c|}{$\begin{array}{c}500^{\circ} \mathrm{C} \\
1340 \mathrm{~min}\end{array}$}} & \multicolumn{4}{|c|}{$550^{\circ} \mathrm{C}$} & \multicolumn{6}{|c|}{$600^{\circ} \mathrm{C}$} & \multicolumn{4}{|c|}{$650^{\circ} \mathrm{C}$} \\
\hline & & & & & & & & \multicolumn{2}{|c|}{$40 \mathrm{~min}$} & \multicolumn{2}{|c|}{$1340 \mathrm{~min}$} & \multicolumn{2}{|c|}{$80 \mathrm{~min}$} & \multicolumn{2}{|c|}{$320 \mathrm{~min}$} & \multicolumn{2}{|c|}{$1340 \mathrm{~min}$} & \multicolumn{2}{|c|}{$10 \mathrm{~min}$} & \multicolumn{2}{|c|}{$80 \mathrm{~min}$} \\
\hline$d \AA$ & $I / I_{1}$ & hkl & $d \AA$ & $I / I_{1}$ & hkl & $d \AA$ & $I / I_{1}$ & $d \AA$ & $I / I_{1}$ & $d \AA$ & $I / I_{1}$ & $d \AA$ & $I / I_{1}$ & $d \AA$ & $I / I_{1}$ & $d \AA$ & $I / I_{1}$ & $d \AA$ & $I / I_{1}$ & $d \AA$ & $I / I_{1}$ \\
\hline 2.70 & 100 & 100 & & & & & & & & 2.702 & M & & & 2.704 & M & 2.697 & M & 2.695 & VW 2 & 2.697 & M \\
\hline 2.49 & 60 & 002 & & & & & & & & 2.499 & W & & & 2.499 & W & 2.490 & W & & & 2.490 & $\mathrm{M}$ \\
\hline 2.372 & 70 & 101 & & & & & & & & 2.374 & W & & & 2.373 & W & 2.362 & W & & & 2.362 & $\mathrm{M}$ \\
\hline & & & 2.336 & 14 & 111 & 2.340 & VW & 2.350 & VW & 2.340 & VW & & & 2.340 & VW & & & 2.346 & VW & & \\
\hline & & & 2.023 & 100 & 200 & 2.036 & VW & 2.041 & VW & 2.026 & $\mathrm{~S}$ & 2.022 & $\mathrm{~S}$ & 2.036 & $\mathrm{~S}$ & & & 2.038 & S & & \\
\hline 1.829 & 21 & 102 & & & & & & & & 1.826 & VW & & & 1.833 & VW & 1.829 & VW & & & 1.818 & VW \\
\hline 1.557 & 30 & 110 & & & & & & & & 1.553 & M & & & 1.549 & M & 1.541 & $\mathrm{~S}$ & 1.560 & W 1 & 1.541 & $\mathrm{~S}$ \\
\hline & & & 1.431 & 42 & 220 & & & 1.439 & VW & 1.432 & M & 1.436 & W & 1.434 & M & & & 1.424 & $\mathrm{M}$ & & \\
\hline 1.414 & 21 & 103 & & & & & & & & & & & & & & 1.407 & W & & & 1.407 & W \\
\hline 1.348 & 5 & 200 & & & & & & & & & & & & & & & & & & & \\
\hline 1.320 & 17 & 112 & & & & & & & & 1.324 & W & & & 1.325 & M & 1.316 & W & & & 1.316 & W \\
\hline 1.301 & 7 & 201 & 1.220 & 1 & 311 & & & & & & & & & & & & & & & & \\
\hline 1.186 & 4 & 202 & 1.168 & 11 & 222 & & & & & & & & & 1.174 & W & & & & & & \\
\hline 1.047 & 6 & 203 & & & & & & & & & & & & & & & & & & & \\
\hline 1.019 & 3 & 210 & 1.012 & 4 & 400 & & & & & & & & & 1.018 & VW & & & & & & \\
\hline 0.9984 & 5 & 211 & & & & & & & & & & & & & & & & & & & \\
\hline 0.9345 & 5 & 105 & 0.928 & 0.4 & 331 & & & & & & & & & & & & & & & & \\
\hline 0.8684 & 6 & 213 & $\begin{array}{l}0.905 \\
0.826\end{array}$ & $\begin{array}{l}10 \\
6\end{array}$ & $\begin{array}{l}420 \\
422\end{array}$ & & & & & & & & & $\begin{array}{l}0.909 \\
0.835\end{array}$ & W & & & & & & \\
\hline
\end{tabular}


From these experimental results, the precipitation process may be summarized as follows:

(1) The cubic particles precipitate preferentially at grain boundaries, deformed grain boundaries, and deformation bands (Photos. 1 (a), and 2 (a), and the precipitation starts earlier in cold-rolled strips than in hot-rolled strips (Fig. 1).

(2) The diffraction pattern from particles precipitated in the unrecrystallized region of cold-rolled strips is unclear, and the major peak (interplanar spacing is $2.03 \mathrm{~A}$ ) is hardly recognized even in the stage where precipitation has progressed enough. When the precipitation takes place at grain boundaries in hot-rolled strips, the solute nitrogen $\left(Q_{\mathrm{N}}{ }^{-1}\right)$ decreases slightly, as shown in Fig. 3.

(3) A great number of particles precipitate in the recrystallized grain of cold-rolled strips and in the grain of hot-rolled strips, some in closely spaced rows, some in ill-defined networks, probably delineating subgrains, and some others at random (Photo. 1 (b)). Particles grow slightly and become to take on shape that is more or less recognizable under electron microscope. In this stage, the diffraction pattern of particles consists of continuous and uniform rings with clear peaks (Fig. 2). The $Q_{\mathrm{N}}{ }^{-1}$ decreases rapidly as the precipitation of cubic particles progresses in grain matrix and grain boundary, and approaches constant value (Fig. 3). Also, the $\mathrm{N}$ as AlN changes, corresponding to $Q_{\mathrm{N}}{ }^{-1}$, but decreases slightly even after $Q_{\mathrm{N}}{ }^{-1}$ has stopped increasing.

(4) The AlN precipitates change from cubic to hexagonal. As the change of particle size or shape is not apparent, however, this change to hexagonal can be seen only by the change in the diffraction pattern and not by metallography (Photos. 1 (c) and 2 (c)). The $Q_{\mathrm{N}}{ }^{-1}$ increases slightly in this stage (Fig. 3).

(5) Hexagonal particles grow gradually with the increase of temperature or time, and the particle shape has become to be clearly recognized (Photos. 1 (d) and 2(d)). The diffraction pattern changes to spotty from uniform ring. The $\mathrm{N}$ as $\mathrm{AlN}$ by chemical analysis increases slightly even in this stage, and approaches the Sol. N value.

The recrystallization and precipitation behaviors in continuous heating are shown in Figs. 4, 5, and 6. From these experimental results, it will be seen that (i) both the cubic and hexagonal precipitate more rapidly with the increase of aluminum contents (Figs. 4 and 5); (ii) the beginning temperature of recrystallization decreases with the increase of aluminum contents if a great number of particles have already been precipitated in the unrecrystallized region (Figs. 4 and 5) ; (iii) when heating rate is fast, the recrystallization progresses before the precipitation of particles has progressed to any considerable degree, but ceases when some precipitates have appeared, and the precipitation progresses while the recrystallization has been stopped. The recrystallization is resumed to completion after enough precipitation has occurred due probably to the growth of the particles (Fig. 6); and (iv) other characteristics of recrystallization, such as changes in grain size, elongation ratio, and diffrac-

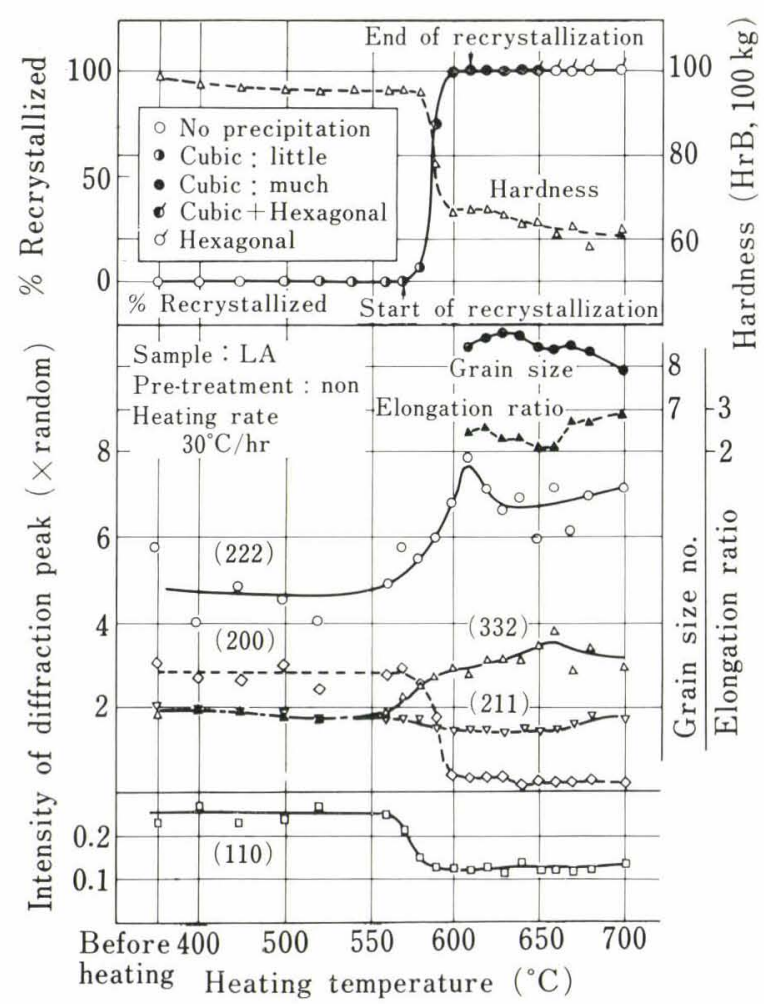

Fig. 4. Change in precipitation, diffracted pole intensity, $\%$ recrystallized, hardness, and grain size and its elongation ratio during continuous heating (steel LA, no pretreatment, $30^{\circ} \mathrm{C} / \mathrm{hr}$ )

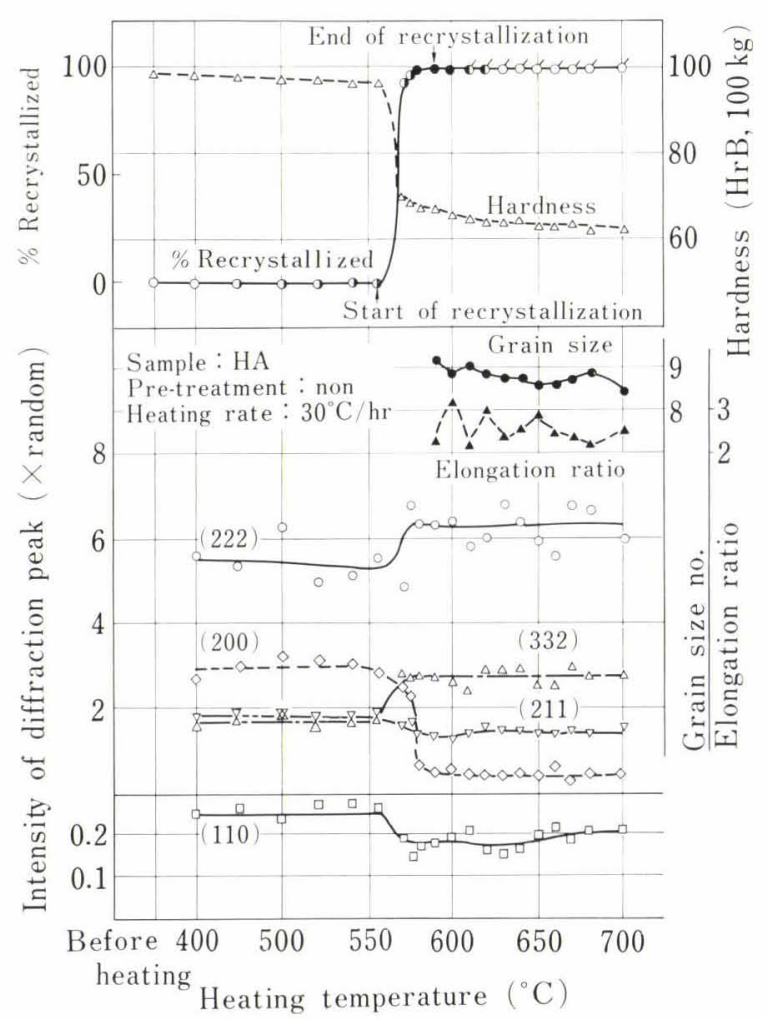

Fig. 5. Change in precipitation, diffracted pole intensity, \% recrystallized, hardness, and grain size and its elongation ratio during continuous heating (steel $\mathrm{HA}$, no pretreatment, $30^{\circ} \mathrm{C} / \mathrm{hr}$ )

tion pole intensities, are as shown in Figs. 4, 5, and 6 . 


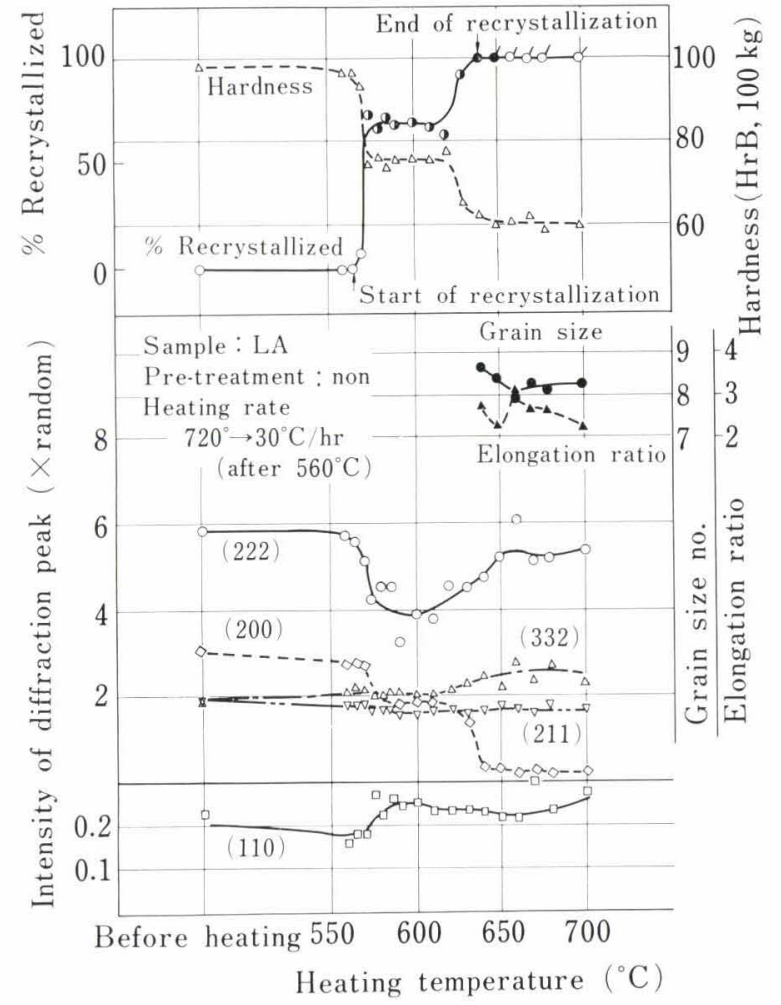

Fig. 6. Change in precipitation, diffracted pole intensity, \% recrystallized, hardness, and grain size and its elongation ratio during continuous heating (steel $\mathrm{LA}$, no pretreatment, $720^{\circ} \mathrm{C} / \mathrm{hr}$ to $560^{\circ} \mathrm{C}, 30^{\circ} \mathrm{C} / \mathrm{hr}$ thereafter)

\section{Discussion}

\section{Crystallographic Analysis of Early Precipitates}

The diffraction pattern of the " cubic precipitates" as shown in Fig. 2, and Tables 2 and 3 has its strongest peak at an interplanar spacing $(d)$ of $2.023 \mathrm{~A}$, and the next intensity at $d=1.431 \mathrm{~A}$. This diffraction pattern does not conform to those of carbo-nitrides of aluminum, iron, or manganese as charted up to this time. Several of the interplanar spacings of cubic precipitates can be seen as conforming to those of iron and other iron-like body centred cubic metals, to those of aluminum and other alminum-like face centred cubic metals, or to those of $\mathrm{Fe}_{3} \mathrm{Al}$. However, if iron, the intensity at $d=1.1702 \AA$ should be stronger than at $d=1.4332 \AA$, besides the one, at $d=2.336 \AA$, is totally missing. Further, no precipitate of this kind has been found in rimmed steels. Therefore, it cannot be said that this cubic precipitate is iron or other b.c.c. metals that have similar lattice constant as iron.

Though the interplanar spacing of aluminum fit with that of the cubic precipitate in question, the intensity ratio for lattice planes for aluminum is wrong for that of this cubic precipitate. Namely, in f.c.c. metals, the diffraction is impossible except when all of the Miller indices h, k, l are odd or even, and the intensity of $\{111\}$ is the strongest but that of $\{200\}$ is weak. However, in this cubic precipitate, mixed indices lines are present, and the intensity of $\{111\}$ is very weak while that of $\{200\}$ is the strongest. Consequently, cubic precipitates cannot be identified with aluminum or f.c.c. metals. Also, $\mathrm{Fe}_{3} \mathrm{Al}$ cannot be this cubic precipitate, judging from the intensity ratio.

In the kinematical theory of diffraction, the integrated intensity of diffraction peak of $\{\mathrm{hkl}\},\left(I_{\mathrm{hl} 1}\right)$, is given by, ${ }^{21)}$

$$
I_{\mathrm{hk} 1}=I_{n} \cdot\left|F_{\mathrm{hk} 1}\right|^{2} \cdot m \cdot \lambda^{3} \cdot V / 16 \cdot \pi \cdot v^{2} \cdot \sin ^{2} \theta \cdot L
$$

where,

$I_{0}$ : the intensity of incident electron beam,

$F_{\mathrm{hkl}}$ : the structure factor of $\{\mathrm{hkl}\}$,

$m$ : the multiplicity factor of $\{\mathrm{hkl}\}$,

$V$ : the volume of a crystal,

$v$ : the volume of a unit cell,

$\theta$ : Bragg angle,

$\lambda$ : the wave length of electron beam, and

$L:$ the distance between a crystal and the photographic plate.

The intensity ratio is proportional to $m\left|F_{\mathrm{hk} 1}\right|^{2} / \sin ^{2} \theta$ if the conditions of measurements are the same. Because the diffraction pattern of cubic precipitates is of the uniform ring, because the intensity ratio of diffraction pattern is the same everywhere along any ring, and because those cubic precipitates are very fine(several tens of $\mathrm{A}$ ), it may be postulated that the cubic precipitates are randomly oriented fine crystals. Accordingly, Eq. (1) can be applied to assess the intensity ratio of diffraction peak.

On the other hand, the diffraction pattern of the cubic precipitates fits very well with that of $\mathrm{NaCl}$ structure. The sturcture factor of $\mathrm{NaCl}$ structure is strong when all of the Miller indices h, k, 1 are even, and weak when all odd. Assuming that the cubic precipitates do have $\mathrm{NaCl}$ structure, the lattice constant is $a=4.047 \AA$.

Nextly, we consider the composition of the cubic precipitates. It may be said that the cubic precipitates contain nitrogen, because the solute nitrogen, as detected by internal friction measurements, does decrease with the detection of $\mathrm{N}$ as AIN by chemical analysis in the stage where the cubic precipitates start appearing. It can be said further that the cubic precipitates contain aluminum from the fact that there are cubic precipitates in aluminum-killed steels although no cubic precipitates occur in rimmed steels, and also that the precipitation of the cubic precipitates depends upon aluminum contents. From these facts, and on the assumption that cubic precipitates are AlN of $\mathrm{NaCl}$ structure $(a=4.047 \AA)$, we calculate the intensity ratio for the diffraction peaks according to the Eq. (1), where $\lambda=0.037 \AA$ (for the accelerating voltage of $100 \mathrm{kV}), f_{\mathrm{Al}}$ and $f_{\mathrm{N}}$ are atomic scattering amplitudes for aluminum and nitrogen atom due to J. A. Ibers et al. ${ }^{22)}$ The results are as shown in Tables 2 and 3, where it will be observed that the measured values fit well with the calculated.

It may be demonstrated that $\mathrm{AIN}$ of $\mathrm{NaCl}$ structure is reasonable from viewpoint of atomic radius. There are TiC, TiN, ZrC, ZrN, VG, VN, NbG, and NbN precipitating in $\mathrm{NaCl}$ type crystals, and both atoms, metallic and carbon (or nitrogen), in those compounds are the cubic close packing, carbon (or nitrogen) of the smaller atomic radius coordinating octahedrally. 
Let us presumed, from hexagonal $\mathrm{AlN}$, that the atomic radius of aluminum is $1.21 \AA$ when nitrogen radius is $0.70 \mathrm{~A}$, as calculated from the lattice constant ( $a=$ 3.114 A, $c=4.986$ A, ASTM Card No. 8-262). Let us suppose now that the atomic radius of nitrogen is $0.70 \AA,{ }^{23)}$ and that the chemical bond is covalent or something similar to it. Then, calculations show that the lattice constant of $\mathrm{AlN}$ in $\mathrm{NaCl}$ type structure should be $a=3.82 \mathrm{~A}$, a value that is somewhat smaller than $a=4.047 \AA$ that was measured.

After Pauling, ${ }^{23)}$ however, it may be stated that this radius of aluminum in AlN bond, which may well be strong ionic in nature because the electronegativity will be great, is an underestimate than when in the single bond, and that the possible increase in the single bond radius for aluminum due to the interatomic metallicity that is associated with the change to the cubic close packing from $(n s)^{\mathbf{1}}(n p)^{\mathbf{3}}$ tetrahedral bonding is not considered. Taking those into consideration and assuming that the single bond radius of aluminum $\left(r_{\mathrm{Al}}\right)$ is $1.248 \AA$, that for nitrogen $\left(r_{\mathrm{N}}\right)$ is $0.70 \AA$, the electronegativity for aluminum $\left(x_{A 1}\right)$ is 1.5 , and that for nitrogen $\left(x_{\mathrm{N}}\right)$ is 3 . The distance in the AlN bond $r_{\mathrm{AIN}}$ would be

$$
r_{\mathrm{A} I \mathrm{~N}}=r_{\mathrm{A} 1}+r_{\mathrm{N}}-0.08\left|x_{\mathrm{A} 1}-x_{\mathrm{N}}\right|=1.828(\AA) .
$$

Moreover, if the valence of aluminum is 3 and with six nitrogen atoms in octahedral coordinating position, then the bond number $(n)$ is $n=3 / 6$. Accordingly, the distance of AlN bond $\left(R_{\text {AIN }}\right)$ would be

$$
R_{\mathrm{AIN}}=r_{\mathrm{AIN}}-0.06 \log n=2.008(\AA),
$$

and the lattice constant would then be $4.02 \AA$. This value is close enough to the measured value to underwrite that $\mathrm{AlN}$ of $\mathrm{NaCl}$ structure is reasonable.

Finally, it should be pointed out that the structure of cubic AlN is similar to that of hexagonal AlN. The hexagonal AlN has aluminum atoms on close packed hexagonal lattice sites and nitrogen atoms at intermediate sites, where each atom is surrounded symmetrically by four atoms of the other kind. The cubic AIN, on the other hand, may be considered as two interpenetrating f.c.c. lattices of aluminum and nitrogen, where each atom is mutually in the octahedral position. Those two, therefore, should be able to transform into each other with little atomic displacement. It is interesting to note that $\mathrm{MnS}$ has both $\mathrm{NaCl}$ structure and Wurtzite structure.

However, the octahedral bond of $(3 d)^{2}(4 s)^{1}(4 p)^{3}$ type is impossible for aluminum, because the aluminum atom lacks the $d$-shell. Accordingly, it may be presumed that cubic AIN has a strong nature of metallic bond, because in it aluminum atoms occupy f.c.c. positions and nitrogen atoms of the smaller atomic radius the octahedral positions. On the other hand, the hexagonal AIN has a nature of covalent bond with $(2 s)^{1}(2 p)^{3}$ tetrahedral bonds. Consequently, inasmuch as aluminum exists in f.c.c., it may be that AlN should exist in $\mathrm{NaCl}$ structure with nitrogen atoms on the octahedral positions of the f.c.c. lattice of aluminum at low temperatures, lower than about the melting point of aluminum, $660^{\circ} \mathrm{C}$, and that AlN at high temperature should be of a stable compound of covalent bonds with aluminum atoms on close packed hexagonal positions. One evidence for this is that the temperature of change from cubic to hexagonal is about $650^{\circ} \mathrm{C}$ (Figs. 4, 5, and 6).

The residue extracted by Beeghly method from the sample, in which a great number of the cubic precipitates were recognized by extraction replica method, however, produced no cubic diffraction pattern when examined by X-ray diffraction method.

\section{Change of Structure and Precipitation Behavior}

It has now been concluded from experimental results of $I I I$ and discussion of $I V-1$ that AIN precipitates into cubic crystal particles before the usual hexagonal AIN becomes prevalent. That those cubic particles should be identified with the postulated clusters or minute particles is supported by the following observation: the solute nitrogen determined by internal friction method decreases as particles are become detected by extraction replica method, as shown in Fig. 3 ; the precipitation is dependent upon the quantity of precipitation sites as shown in Fig. 1, and by amount of aluminum available for reaction; and recrystallization behavior is influenced by precipitation.

However, as mentioned earlier, the diffraction pattern taken in an early stage of precipitation of those particles precipitating at grain boundaries, deformed grain boundaries, or deformation bands is not as clearly defined as that taken when a great number of particles have precipitated in the already recrystallized grains. Even then, that those particles are AlN of NaCl structure is clear because an intensity peak does appear at $d=2.027 \AA$, which is the strongest line from $\mathrm{NaCl}$ structure, and, as the precipitation progresses, not only does it become clearer but other lines become discernible, though never as well defined as those from the particles precipitated in already recrystallized grains. The reason for this may be simply that the number of particles participating in diffraction is insufficient, yet this leaves some doubt if the particles precipitating before or after recrystallization might have different structures.

Now, we shall consider the change to hexagonal from cubic. It was often seen in the examination of distribution of particles by extraction replica method that particles appeared to lose their definition somewhat and the lineage alignment became at random in the stage of change to hexagonal was taking place, and that the solute nitrogen increased slightly as shown in Fig. 3. From those observations, it is possible to postulate that hexagonal particles reprecipitate after cubic precipitates have been dissolved. It suggests the reversion of AlN, such that, as witnessed by Ichiyama et al. with $\mathrm{Fe}-\mathrm{Al}-\mathrm{N}$ alloys containing $0.1 \%$ aluminum, ${ }^{24}$ AlN precipitation decreased slightly at $650^{\circ} \mathrm{C}$.

However, the change in the distribution of particles detected by extraction replica method is little, the decrease in the precipitates, as seen by replica, being very little, and the change to hexagonal can only be recognized by diffraction pattern. Thus, inasmuch 
as (1) the change from cubic to hexagonal can occur with little atomic displacement, (2) though the distribution of particles should change perceptibly if new particles were to precipitate on new precipitation sites, the distribution of particles scarcely changes actually, and (3) should the cubic particles act as nuclei for the precipitates newly forming in the course of reversion, the particles would find it difficult to transform from cubic to hexagonal, any mechanism based on reversion would be unlikely. Therefore, the change from cubic to hexagonal is probably due to crystallographic transformation.

\section{Summary}

Where only hexagonal AlN particles have been detected in aluminum-killed steels, and either minute particles or clusters of aluminum and nitrogen, such that not to be detected by chemical analysis, by extraction replica method, or by direct observation of thin foils, have been postulated to exist before the precipitation of hexagonal AlN particles, the authors have been able to recognize minute precipitates in such a stage.

The precipitation characteristics of the minute particles are as follows ;

(1) The particles increase their number as the solute nitrogen decreases.

(2) Precipitation is enhanced with the increase of precipitation sites.

(3) The minute particles precipitate preferentially at grain boundaries or on deformation bands.

(4) Precipitation is enhanced with the increase of aluminum contents.

(5) The diffraction pattern of minute particles precipitated in the unrecrystallized region is unclear.

(6) Many particles tend to precipitate into rows in the recrystallized region, to sizes of several tens of $\mathrm{A}$, then the diffraction pattern is clear and well defined.

(7) The minute particles are most probably AlN of $\mathrm{NaCl}$ structure.

(8) Those cubic precipitates cannot be detected in rimmed steel.

(9) The solute nitrogen increases slightly in the stage where cubic crystal particles change to hexagonal ones.

(10) Change to hexagonal from cubic is probably by transformation without reversion.

(11) When the recrystallization proceeds after many cubic particles have been precipitated in unrecrystallized matrix, the beginning temperature of recrystallization decreases with the increase of aluminum contents.

(12) When heating rate is fast, the recrystallization proceeds while the number of precipitated cubic AlN particles is yet small, but ceases as more particles have appeared; it is resumed to completion after enough precipitation has occurred due probably to the growth of the particles.

\section{Acknowledgements}

The authors wish to express their gratitude to Professor H. Abe of University of Tokyo for his helpful advices and discussions. Also, they are deeply indebted to Mr. Y. Saziki of their Laboratory for X-ray measurements and to their many colleagues for the assistance.

\section{REFERENCES}

1) R.S. Burns and A.S. McCabe: U.S. Patent 2381435 (Aug. 7, 1945)

2) R. L. Rickett, S. H. Kalin, and J. T. Mackenzie: Trans. Met. Soc. AIME, 185 (1949), 242.

3) R. L. Solter and C. W. Beattie: Trans. Met. Soc. AIME, 191 (1951), 721

4) W. C. Leslie, R. L. Rickett, C. L. Dotson, and C. S. Walton: Trans. ASM, 46 (1954), 1470.

5) K. Aoki, S. Sekino, and T. Fujishima: J. Japan Inst. Metals, 26 (1962), 437.

6) K. Aoki, S. Sekino, and T. Fujishima: J. Japan Inst. Metals, 26 (1962), 678.

7) M. Shimizu, K. Matsukura, N. Takahashi, and Y. Shinagawa: Tetsu-to-Hagané, 50 (1964), 2094.

8) M. Shimizu, K. Matsukura, N. Takahashi, and Y. Shinagawa: Tetsu-to-Hagané, 50 (1964), 2097.

9) H. Borchers and Z. Q. Kim: Arch. Eisenhüttenwes., 36 (1965), 311.

10) H. Borchers and Z. Q. Kim: Arch. Eisenhüttenwes., 37 (1966), 161.

11) K. Matsudo: Sosei to Kako (J. Japan Soc. Tech. Plasticity), 7 (1966), 376.

12) I. L. Dillamore and S. F. H. Fletcher: Recrystallization, Grain Growth and Textures, (1966), 448, Amer. Soc. Metals.

13) R. H. Goodenow: Trans. Met. Soc. AIME, 59 (1966), 804.

14) C. A. Stickles: Trans. Met. Soc. AIME, 236 (1966), 1295.

15) P. N. Richards: J. Australian Inst. Metals, 12 (1967), 2.

16) S. Hanai and O. Akisue: J. Japan Inst. Metals, 32 (1968), 345.

17) F. A. Hultgren: Blast Furn. Steel Pl., 56 (1968), 149.

18) J. T. Michalak and R. D. Schoone: Trans. Met. Soc. AIME, 242 (1968), 1149.

19) H. Abe and T. Suzuki: Tetsu-to-Hagané, 56 (1970), 869.

20) H. F. Beeghly: Analy. Chem., 21 (1949), 1513.

21) S. Takagi: Kessho Kaiseki, (1968), 172, Asakura Shoten, (in Japanese).

22) J. A. Ibers and B. K. Vainshtein: International Crystallographic Tables, Vol. III, (1962), Table 3. 3. 3 A(1) A(2), Kynoch Press.

23) L. Pauling: The Nature of Chemical Bond, Third Edition, (1960), Cornell University Press.

24) T. Ichiyama, M. Koizumi, I. Yoshida, K. Watanabe, and S. Nishiumi: Tetsu-to-Hagané, 55 (1969), 1229. 